\title{
Assessment of disease lesion removal as a method to control chronic Montipora white syndrome
}

\author{
Silvia Beurmann ${ }^{1,2, *}$, Christina M. Runyon ${ }^{1,2}$, Patrick Videau ${ }^{3}$, Sean M. Callahan ${ }^{1,2}$, \\ Greta S. Aeby ${ }^{2}$ \\ ${ }^{1}$ University of Hawai'i at Mānoa, Department of Microbiology, Honolulu, HI 96822, USA \\ ${ }^{2}$ Hawai'i Institute of Marine Biology, Honolulu, HI 96744, USA \\ ${ }^{3}$ Dakota State University, College of Arts and Sciences, Madison, SD 57042, USA
}

\begin{abstract}
Coral colonies in Kāne'ohe Bay, Hawai'i (USA), are afflicted with the tissue loss disease chronic Montipora white syndrome (cMWS). Here we show that removal of chronic disease lesions is a potential method to slow the progression of cMWS in M. capitata. Over the $24 \mathrm{wk}$ observation period, treatment colonies lost almost half the amount of tissue that was lost by control colonies. The percentage of tissue loss at each sampling interval (mean \pm SEM; treatment: $1.17 \pm$ $0.47 \%$, control: $2.25 \pm 0.63 \%$ ) and the rate of tissue loss per day (treatment: $0.13 \pm 0.04 \%$, control: $0.27 \pm 0.08 \%$ ) were both significantly lower on treated colonies than control colonies. While lesion removal stopped tissue loss at the initial infection site, which allowed colony healing, it did not prevent re-infection; in all but one of the treated colonies, new cMWS lesions appeared in other areas of the colony but not around the treatment margins. Additionally, the rate of new infections was similar between treatment and control colonies, indicating that physical injury from lesion removal did not appear to increase cMWS susceptibility. These results indicate that lesion removal reduced morbidity in $M$. capitata exhibiting cMWS but did not stop the disease.
\end{abstract}

KEY WORDS: Coral disease management $\cdot$ Montipora capitata $\cdot$ Infection $\cdot$ Treatment $\cdot$ Hawai'i

\section{INTRODUCTION}

Coral reefs are of great importance to human societies and the myriad reef-dwelling organisms. Reefs protect coastlines from the damaging effects of wave action (Sheppard et al. 2005), provide habitats for marine organisms (Friedlander et al. 2003), and harbor natural resources, such as food and sources of secondary metabolites that can serve as lead compounds for drug discovery (Belarbi 2003, Bellwood et al. 2004). Corals, like all other organisms, are susceptible to disease, and the declining health of reefs has led to disease outbreaks, incidences of which have increased worldwide (Goldberg \& Wilkinson 2004, Bourne 2005, Miller \& Williams 2007). Environmental stressors, including elevated seawater temperatures, nutrient input from runoff, and sedimentation, exacerbate the declining health of corals (Harvell et al. 2007, Dalton et al. 2010, Haapkylä et al. 2011). The tissue-loss disease Montipora white syndrome has impacted the population of M. capitata in Kāne'ohe Bay, Hawai'i (USA), over the last decade (Aeby et al. 2010). Two types of tissue-loss disease have been documented: a progressive infection with diffuse tissue loss termed chronic Montipora white syndrome (cMWS) and a comparatively faster manifestation termed acute Montipora white syndrome (aMWS) (Ushijima et al. 2012). Colonies exhibiting cMWS infections are observed at constant levels throughout the year (Aeby et al. 2010), while aMWS infections 
are seasonal and occur at outbreak levels in the cold, rainy winter months (Aeby et al. 2016). Due to the slow progression of cMWS, colonies exhibiting these lesions can survive with this disease for several months to years (Aeby et al. 2010). In contrast, aMWS can lead to complete colony mortality within a few weeks (Aeby et al. 2016). Field and laboratory observations suggest that corals exhibiting cMWS can switch to the acute disease manifestation, which can result in colony death (Work et al. 2012). Colonies with aMWS have also been observed to revert to cMWS, but the mechanism of switching in either direction remains unknown. The widespread mortality of $M$. capitata colonies in Kāne'ohe Bay and the ability of cMWS lesions to suddenly switch to the acute manifestation of this disease stress the importance of developing a method that reduces the abundance of cMWS-afflicted $M$. capitata colonies, consequently reducing morbidity (defined as infection resulting in partial death of the colony) from disease and decreasing the risk of future aMWS outbreaks (Aeby et al. 2016).

Lesion removal is a common form of medical intervention to cure some diseases affecting both vertebrates and invertebrates. Similar treatment methods employing lesion removal have proven successful for mitigating the damage inflicted by certain coral diseases (Hudson 2000, Dalton et al. 2010, Williams 2013, Aeby et al. 2015). Removing pathogen-afflicted areas of tissue by suction and covering the affected area with modeling clay was $70 \%$ effective in controlling black band disease on affected Oscillatoria membrancea in the Florida Keys (Hudson 2000). Application of a double band of marine epoxy mixed with chlorine powder to the black band disease front significantly reduced $M$. capitata colony mortality by $30 \%$ compared to non-treated colonies in Kaua'i, Hawai'i (Aeby et al. 2015). Another study revealed that removing the disease front of a tissue loss disease affecting Turbinaria colonies in Australia effectively halted disease progression in $80 \%$ of the colonies (Dalton et al. 2010). In addition, removal of growth anomalies on branching acroporids in the central Pacific (Northern Line Islands) resulted in $90 \%$ of colonies remaining disease free for 9 mo posttreatment (Williams 2013). Because corals are efficient at healing injuries (i.e. re-growth of tissue) (Henry \& Hart 2005, Work \& Aeby 2010), the burden of healing wounds created by the removal of disease lesions should not have long-term impacts on the coral colonies. Although potentially confounding evidence has been reported that wounds can increase susceptibility to some diseases (Aeby \& Santavy
2006, Page \& Willis 2008), the above-mentioned treatments remain a potentially important means of containing some types of disease outbreaks in the short term. The increasingly numerous records of successful disease treatments will aid resource managers in addressing the growing threat of coral disease outbreaks.

While morbidity- and mortality-reducing techniques have been developed for many plant and animal species (Nandakumar et al. 2001, Warrell et al. 2008), only a few are available for corals. Therefore, our objective was to test lesion removal as a method of disease treatment to reduce morbidity or mortality from tissue loss associated with cMWS lesions.

\section{MATERIALS AND METHODS}

\section{Study sites}

Experimental manipulations were conducted in Kāne'ohe Bay, O'ahu, Hawai'i, an intricate estuarine system with a barrier coral reef and various patch and fringing reefs (Hunter \& Evans 1995). The 5 study sites were separated by a minimum of $150 \mathrm{~m}$ and were located on the southern, eastern, and western regions of the fringing reef surrounding the island of Moku o Lo'e in south Kāne'ohe Bay (Fig. 1). These fringing reefs have relatively low coral diversity and are dominated by 2 coral species, namely Porites compressa and Montipora capitata (Aeby et al. 2010). This study focused on coral communities on the shallow $(<5 \mathrm{~m})$ fringing reefs.

\section{Experimental removal of cMWS lesions}

cMWS is a common disease of $M$. capitata in Kāne'ohe Bay, and cMWS lesions are observed persistently (average prevalence ranged from 0.02 to $0.87 \%$ ) in coral populations with no seasonal variation (Aeby et al. 2010). In May 2014, a total of $20 \mathrm{M}$. capitata colonies with cMWS were chosen haphazardly: 10 as treatment colonies and 10 corresponding control colonies with lesions of comparable size located near each treatment colony $\left(4\right.$ site $\left.^{-1}\right)$. To facilitate complete lesion removal with minimal damage to the parent colony, only colonies displaying cMWS lesions of 1 to $5 \mathrm{~cm}^{2}$ were chosen. All colonies were tagged, photographed, and their positions recorded using GPS. The disease lesions, as well as roughly $2 \mathrm{~cm}$ of adjacent healthy tissue to ensure complete lesion removal, were removed from the treatment 

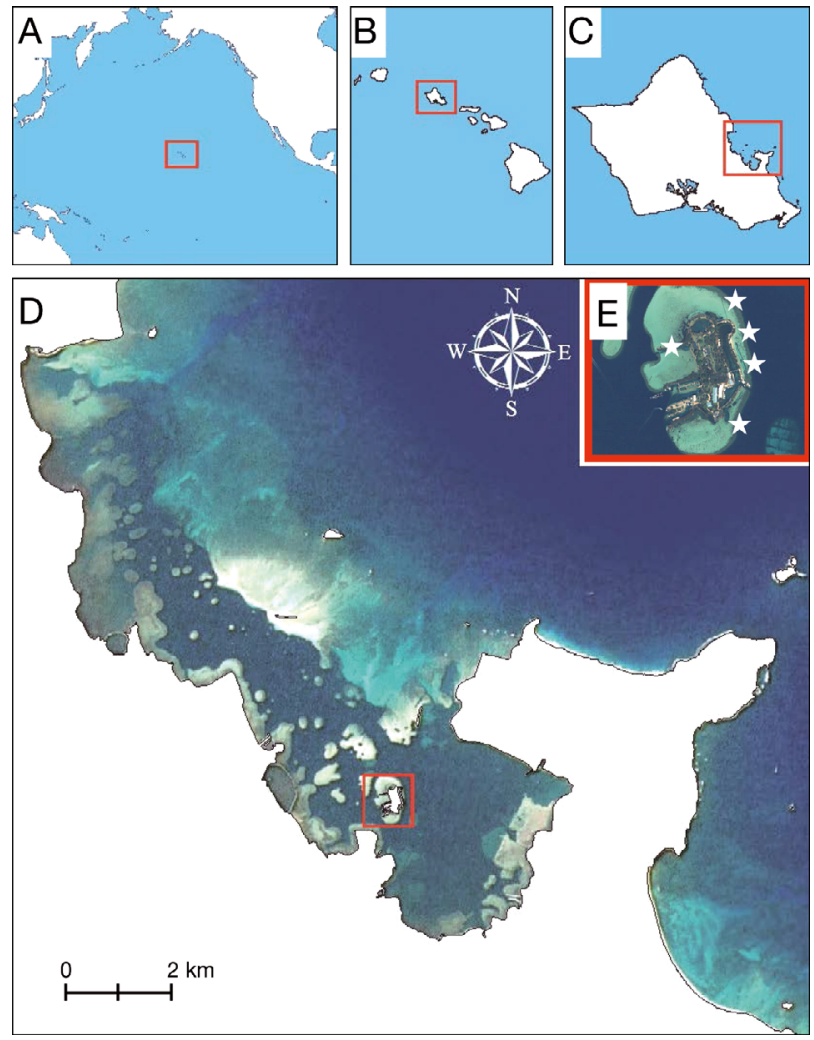

Fig. 1. (A) Hawai'i, (B) O'ahu, (C) Kāne'ohe Bay, (D) Moku o Lo'e. (E) The study focused on coral colonies at 5 sites (stars) on the shallow fringing reefs of Moku o Lo'e

colonies using bone shears. $M$. capitata has a soft skeleton, and sections can be removed easily with minimal harm to the colony. All extracted diseased fragments were immediately quarantined in Ziploc bags at depth following removal and were sterilized with a $5 \%$ sodium hypochlorite solution upon return to the laboratory. The control colonies were left untreated. For $24 \mathrm{wk}$, all colonies were examined weekly for progressive tissue loss or the development of new lesions, and all occurrences were photo-documented (Fig. 2). The complex structure of the M. capitata colonies precluded the use of digital measurements to estimate rates of tissue loss. Hence, in situ observations on the proportion of the colony that was healthy, diseased, or dead was recorded during each survey period.

\section{Data analyses}

Due to the ordinal nature of the single dependent variable (tissue loss), and the relatively small and unequal sample sizes (2 levels: treated and control colonies), a non-parametric Mann-Whitney $U$-test was used to assess the effect of treatment on the total loss of healthy tissue from infected colonies. The relative prevalence of disease represents the proportion of colonies (controls or treatments) that showed active cMWS lesions at the time of survey. A repeated measures MANOVA was used to compare the rates of tissue loss and the percentages of tissue loss through time between the control and treatment colonies. The rate of tissue loss was assessed for each colony by comparing the percentage of diseased tissue at the beginning and end of each individual sampling period and expressing the rate as a daily percentage of tissue lost. These data consist of repeated measures that are dependent levels of 1 independent variable. Although the residuals follow a pattern that satisfies a normal distribution when analyzed on a Q-Q plot, compound symmetry was not met (Mauchly's sphericity: $\chi^{2}=490.56$, df $=90, \mathrm{p}<0.01$ ), so a repeated measures MANOVA test was used. Statistical analyses were conducted using the PRISM7 (GraphPad Software) and JMP12 (SAS Institute) software packages.

\section{RESULTS}

Due to environmental and anthropogenic factors (i.e. reef damage from boat strikes and reef collapse due to storms), the initial sample size of 10 for each group was reduced to 7 for the control and 8 for the treatment colonies. Within the treatment group, no further tissue loss occurred in the area of lesion removal. All wounds created from treatment healed and were grossly covered with tissue within $5 \mathrm{wk}$ post-removal. In contrast, lesions present within the control group continued to progress over the course of the study. Lesion removal did not prevent re-infection, and the disease reoccurred in some treatment colonies as early as $7 \mathrm{~d}$ post-treatment and continued through time. After $24 \mathrm{wk}$, all of the control colonies $(n=7)$ and 7 of the 8 treatment colonies exhibited new lesions, and the relative percentages of disease prevalence displayed similar trajectories between treatment and control colonies (see Fig. 4B). Reinfections did not occur around the treatment margins but only on other areas of the colony.

Within the 24 wk observation period, lesion removal resulted in reduced morbidity in treatment colonies. An assessment of the initial and final percentages of tissue loss showed that treatment colonies lost almost half the amount of tissue that was lost by control colonies, a mean total of $48 \%$ less tissue (Fig. 3A; mean \pm SEM: treatment colonies $15.25 \pm$ 

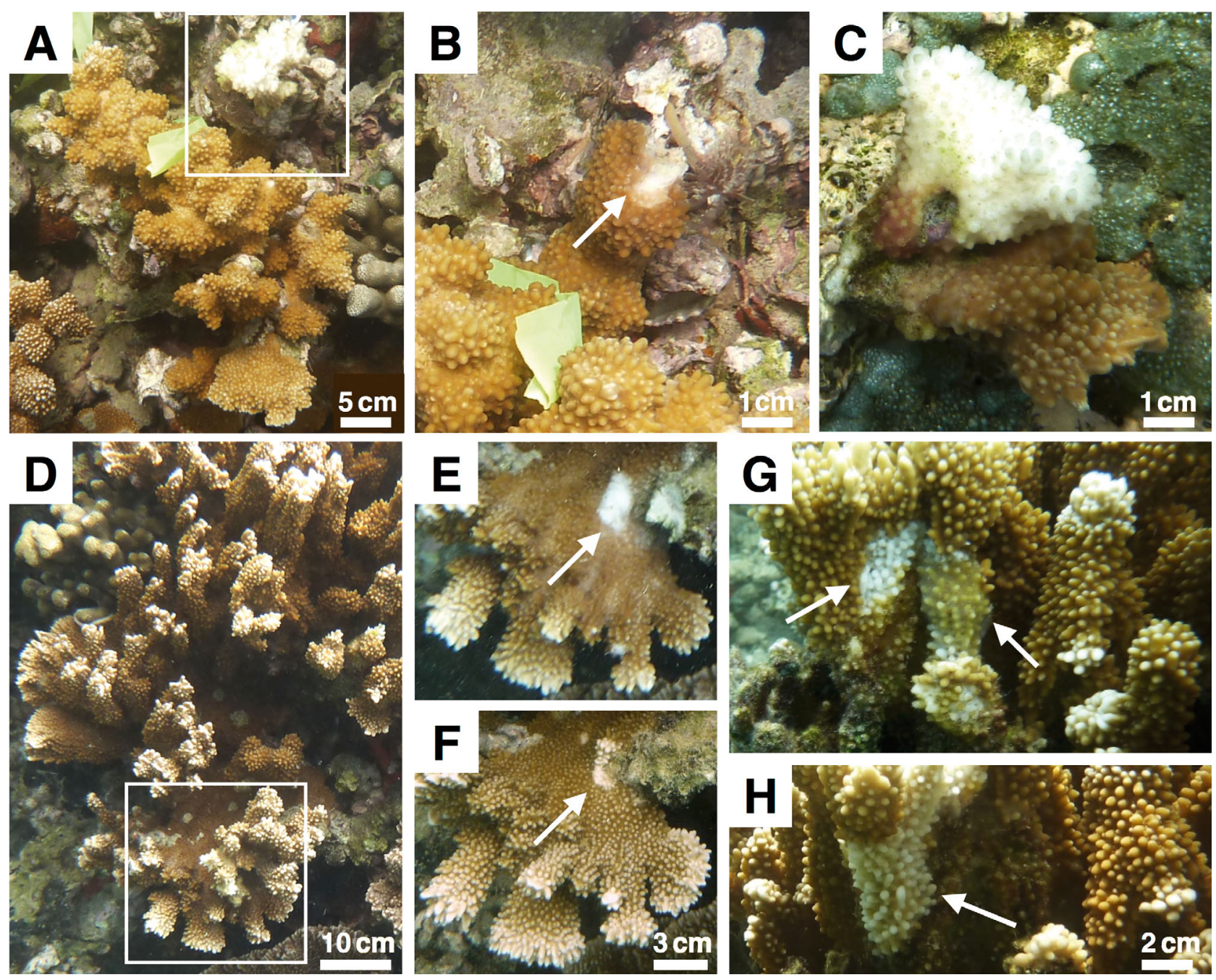

Fig. 2. Lesion removal in Montipora capitata colonies affected by chronic Montipora white syndrome (cMWS). (A-C) M. capitata colony showing positive response to lesion removal: (A) May 2014, cMWS lesion present (box); (B) wound left after removal of lesion in May 2014 (arrow); (C) lesion. (D-H) M. capitata showing development of new cMWS lesions after treatment: (D) May 2014, cMWS lesion present (box); (E) wound left after lesion removal in May 2014 (arrow); (F) re-growth of healthy tissue over wound within 5 wk post-lesion removal (arrow); $(G, H)$ development of new cMWS lesions on other areas of the colony (arrows)

$3.89 \%$, control colonies $29.29 \pm 5.53 \%$ ), but this difference was not statistically significant (Mann-Whitney, $\left.U=13.5, \mathrm{n}_{\text {control }}=7, \mathrm{n}_{\text {treatment }}=8, \mathrm{p}=0.101\right)$. Comparison of the mean percent tissue loss at each sampling interval displayed a statistically significant decrease in tissue loss by treatment colonies $(1.17 \pm$ $0.47 \%)$ compared to control colonies $(2.25 \pm 0.63 \%)$ over the course of the experiment without accounting for time (Fig. 3B; repeated measures MANOVA $\left.(\mathrm{rmMANOVA}): F_{13,1}=1239.1, \mathrm{p}=0.022\right)$. Once time was accounted for, a statistically significant interaction effect between the percentage of tissue loss and time was also observed (rmMANOVA: $F_{13,1}=1191.3$, $\mathrm{p}=0.023)$. The average rate of tissue loss through the duration of the study, calculated as the percent tissue loss per day in Fig. 4A, was also significantly lower on the treatment colonies $(0.13 \pm 0.04 \%)$ compared to the control colonies $(0.27 \pm 0.08 \%$; rmMANOVA: $F_{1,13}=8.3, p=0.013$ ). The rate of tissue loss was calculated for each individual sampling interval, rather than over the entire experimental time course, and a comparison of these rates showed a significant difference along a fine time scale (rmMANOVA: $F_{1,12}=20$, $\mathrm{p}=0.049$ ). By comparing daily rates of tissue loss between sampling intervals, a spike in the rate of tissue loss was observed in both groups with a maximum in Week 6. Interestingly, 1 of the control colonies exhibited the signs of a switch from a chronic to 

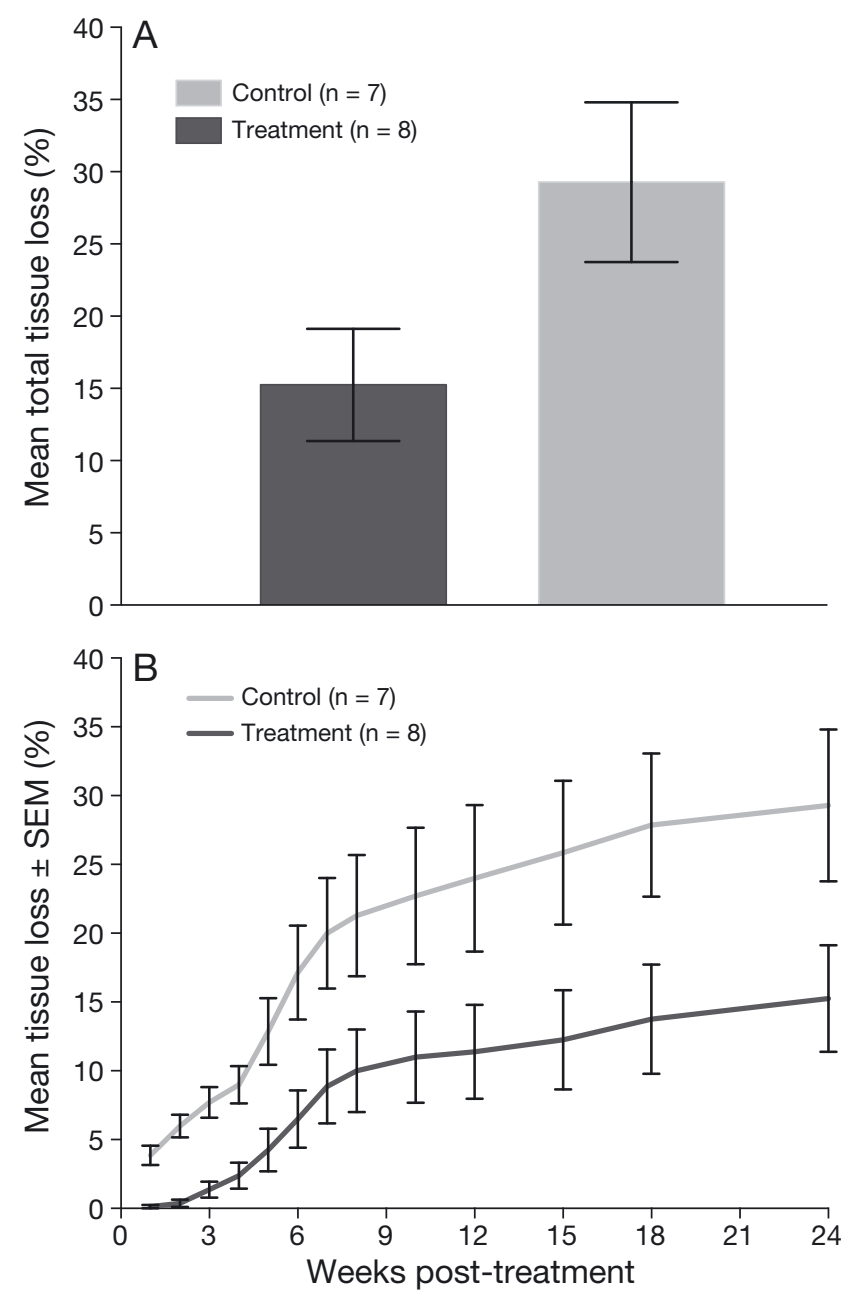

Fig. 3. (A) Total tissue loss from Montipora capitata colonies affected by chronic Montipora white syndrome. Tissue loss is presented as the mean \pm SEM after $24 \mathrm{wk}$ post-treatment from control colonies and those treated via lesion removal. (B) Mean \pm SEM percent tissue loss on $M$. capitata treatment colonies (lesions removed, $\mathrm{n}=8$ ) and control colonies (lesions left in place, $\mathrm{n}=7$ ) throughout the $24 \mathrm{wk}$ study period

an acute lesion in the last sampling interval, but no acute tissue loss lesions were observed on the treatment colonies. Despite the increased rate of tissue loss from aMWS infections, the late timing of the switch in disease state did not alter the average rates of tissue loss calculated.

\section{DISCUSSION}

In this study, we applied a lesion-removal technique to cMWS-infected Montipora capitata colonies to assess its viability as a treatment measure. Lesion removal stopped tissue loss at the initial site of infection, and all wounded colonies healed
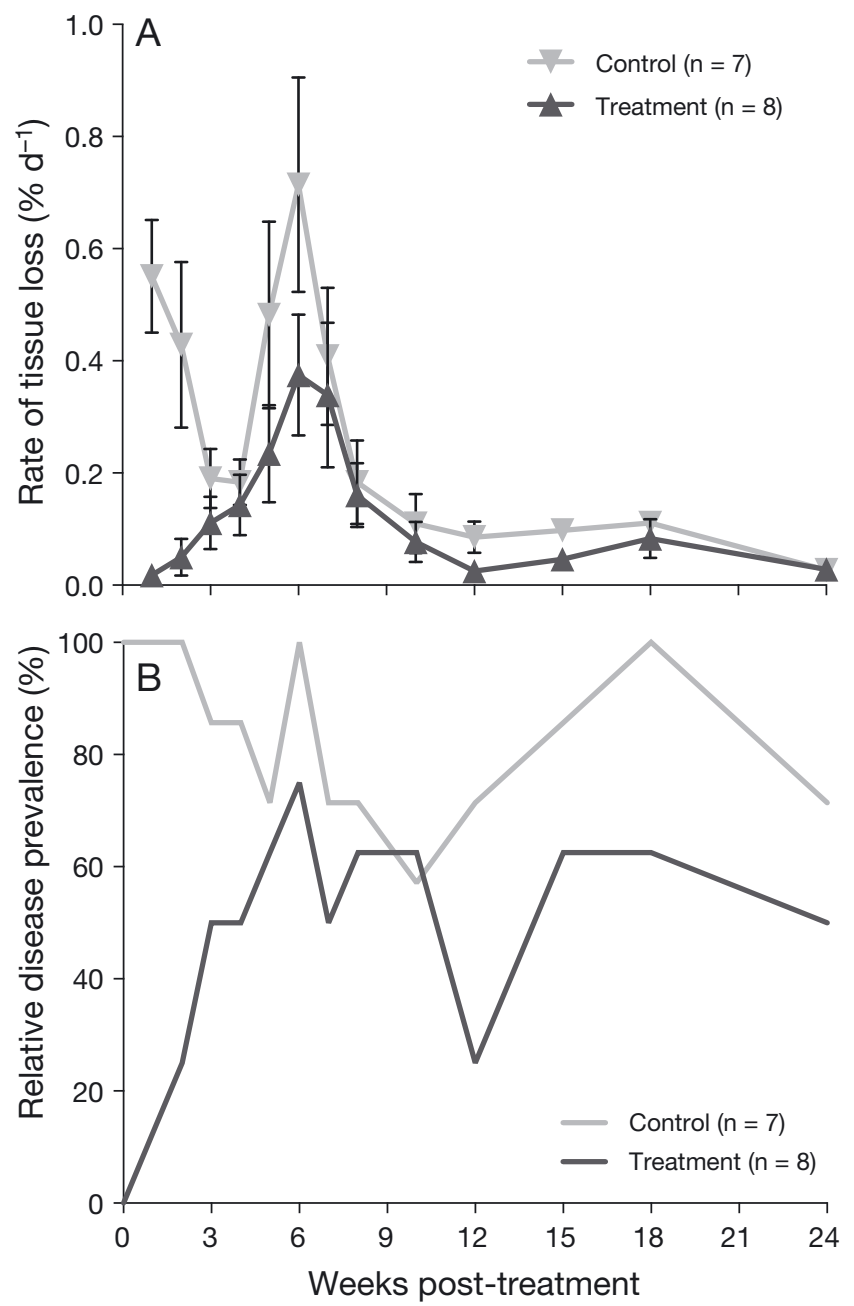

Fig. 4. (A) Rate of tissue loss, calculated as the percent tissue loss per day across each sampling interval, and (B) relative disease prevalence of active chronic Montipora white syndrome lesions through time on treated (lesions removed) and control (lesions left in place) $M$. capitata colonies during the 24 wk study period

within $5 \mathrm{wk}$ of treatment. However, re-infection was observed, and new lesions appeared on other areas of every control colony and all but 1 treatment colony (Fig. 4B). Lesion removal was only performed once in this study, so re-infection resulted in continued tissue loss on treated colonies. Tissue loss resulting from new lesions was likely the reason why the difference in total percent tissue loss did not reach statistical significance. However, even with re-infection of treatment colonies over the $24 \mathrm{wk}$ observation period, control colonies lost nearly twice as much tissue as treated colonies. Despite the likelihood of re-infection, the removal of disease lesions from treatment colonies significantly decreased the rate of tissue loss from 
cMWS on colonies. This suggests that a static endpoint picture of tissue loss is insufficient to describe the dynamics of cMWS infection and spread and the effect of treatment. $M$. capitata grows less than $2.5 \mathrm{~cm} \mathrm{yr}^{-1}$ in Hawai'i (Jokiel 1978), and so tissue loss from disease may require substantial recovery time. These results differ from previous studies in which lesion removal was successful at stopping disease progression. Lesion removal halted white syndrome on Turbinaria mesenterina (Dalton et al. 2010) and growth anomalies on Acropora acuminata (Dalton et al. 2010, Williams 2013). The etiologies and ecologies of diseases differ, which affects the efficiency of any treatment method. The more that is understood about disease ecology, the higher the likelihood of developing an appropriate method of control. Due to the declining state of many coral reefs, a treatment method that reduces morbidity in affected colonies may be warranted.

Previous research has proposed that disruption of the coral animal through mechanical injury increases susceptibility to some diseases (Aeby \& Santavy 2006, Page \& Willis 2008), suggesting that corals are either more susceptible because they have an open wound that can subsequently become infected or that some systemic change takes place to weaken the entire organism, thereby making it generally more susceptible to disease. In our study, although treated colonies were re-infected with cMWS within a few weeks post-lesion removal, new infections never occurred at the removal site, indicating that tissue disruption was not required for cMWS initiation. In addition, the development of new lesions was similar between the 2 groups, suggesting that the processes affecting cMWS pathogenesis continued throughout the experiment regardless of coral wounding.

It is possible that a fundamental difference exists between the fresh wounds and uncompromised areas on treated colonies, because all new cMWS lesions occurred on uncompromised areas of the colonies. Van de Water et al. (2015) examined the regulation of the coral immune response during wound healing in A. aspera. They showed that various components of the innate immune system were upregulated and suggested that an initiated immune response may prevent infection at wound sites. It is not known whether M. capitata responds to wounding in a similar manner. However, the occurrence of new lesions on uncompromised areas of $M$. capitata colonies is more consistent with an existing interaction that sporadically activates rather than opportunistic infections occurring at injury sites.
The data presented here indicate that disease lesions alternated between active (recent tissue loss) and inactive (no recent tissue loss) states in both groups as has been previously reported for this disease (Aeby et al. 2010, Work et al. 2012). In our study, disease prevalence and the rates of tissue loss showed similar temporal patterns for both groups (treatment and control), with spikes in prevalence and lesion rate occurring in Weeks 3 to 8 (Fig. 4). After these spikes, the rate of tissue loss returned to a consistently lower level but prevalence continued to vacillate. The similar temporal pattern of infection among corals suggests that there may be an undiscovered environmental component affecting cMWS processes in $M$. capitata, which could have caused these spikes. Without the temporal resolution afforded by weekly sampling, this short-term increase in infection would have been missed.

In previous work, decreases in morbidity and mortality were recorded following treatment of different types of disease lesions from various coral species (Hudson 2000, Dalton et al. 2010, Williams 2013, Aeby et al. 2015). Each of these studies reported benefits to coral survival as a result of treatment and should be considered as potential management actions in response to disease outbreaks. The differences in coral species, pathogens, and local environmental factors require that treatments be tailored to individual diseases on each coral host. For example, Williams (2013) found that growth anomaly removal was a successful treatment for $A$. acuminata but not for $M$. efflorescens located on the same reef under similar environmental conditions. Although somewhat time consuming, lesion removal would be effective in controlling disease in closed systems such as coral nurseries, at the onset of a disease outbreak, on reefs with a low incidence of cMWS, or for treating colonies that are of the most value to the reef (Raymundo et al. 2008). While lesion removal has proven beneficial for cMWSinfected colonies, management actions that address the overarching drivers of coral disease (e.g. nutrient runoff from human and animal waste, overfishing, and rising surface seawater temperatures) are required to maintain the long-term viability of coral reefs (Bruckner 2002). The complexity of a coral's response to disease, the efficacy of lesion treatment, and the response of different pathogens to treatment are all areas that require further study to refine treatment options. Equally important to the initial disease response, however, is the follow-up research required to identify and understand underlying factors that trigger disease outbreaks. 
Acknowledgements. Funding was provided by NOAA, grant number NA12NOS4820070. This study was conducted under the State of Hawai'i, Department of Land and Natural Resources, Division of Aquatic Resources Special Activities Permits SAP\#2013-47 and SAP\#2015-17. We thank C. Spitzer (Hawai'i Institute of Marine Biology) for field support and Dr. J. Walguarnery (University of Hawai'i at Mānoa, Department of Biology) for assistance with statistical analyses.

\section{LITERATURE CITED}

Aeby GS, Santavy DL (2006) Factors affecting susceptibility of the coral Montastraea faveolata to black-band disease. Mar Ecol Prog Ser 318:103-110

Aeby GS, Ross M, Williams GJ, Lewis TD, Work TM (2010) Disease dynamics of Montipora white syndrome within Kāne'ohe Bay, Oahu, Hawaii: distribution, seasonality, virulence, and transmissibility. Dis Aquat Org 91:1-8

Aeby GS, Work TM, Runyon CM, Shore-Maggio A and others (2015) First record of black band disease in the Hawaiian archipelago: response, outbreak status, virulence, and a method of treatment. PLOS ONE 10:e0120853

Aeby GS, Callahan S, Cox EF, Runyon C and others (2016) Emerging coral diseases in Kāne'ohe Bay, O'ahu, Hawai'i (USA): two major disease outbreaks of acute Montipora white syndrome. Dis Aquat Org 119:189-198

Belarbi EH (2003) Producing drugs from marine sponges. Biotechnol Adv 21:585-598

Bellwood DR, Hughes TP, Folke C, Nyström M (2004) Confronting the coral reef crisis. Nature 429:827-833

Bourne DG (2005) Microbiological assessment of a disease outbreak on corals from Magnetic Island (Great Barrier Reef, Australia). Coral Reefs 24:304-312

Bruckner AW (2002) Priorities for effective management of coral diseases. US Department of Commerce, National Oceanic and Atmospheric Administration, National Marine Fisheries Service. www.bio-nica.info/biblioteca/ bruckner/-managementcoraldisease.pdf

Dalton SJ, Godwin S, Smith SDA, Pereg L (2010) Australian subtropical white syndrome: a transmissible, temperaturedependent coral disease. Mar Freshw Res 61:342-350

Friedlander AM, Brown EK, Jokiel PL, Smith WR, Rodgers KS (2003) Effects of habitat, wave exposure, and marine protected area status on coral reef fish assemblages in the Hawaiian archipelago. Coral Reefs 22:291-305

Goldberg J, Wilkinson C (2004) Global threats to coral reefs: coral bleaching, global climate change, disease, predator plagues and invasive species. In: Wilkinson C (ed) Status of coral reefs of the world 2004, Vol 1. Australian Institute of Marine Science, Townsville, p 67-92

*Haapkylä J, Unsworth RKF, Flavell M, Bourne DG, Schaffelke B, Willis BL (2011) Seasonal rainfall and runoff promote coral disease on an inshore reef. PLOS ONE 6: e16893

‘ Harvell D, Jordán-Dahlgren E, Merkel S, Rosenberg E and

Editorial responsibility: Garriet Smith,

Aiken, South Carolina, USA others (2007) Coral disease, environmental drivers, and the balance between coral and microbial associates. Oceanography 20:172-195

*Henry LA, Hart M (2005) Regeneration from injury and resource allocation in sponges and corals - a review. Int Rev Hydrobiol 90:125-158

Hudson JH (2000) First aid for massive corals infected with black band disease, Phormidium corallyticum: an underwater aspirator and post-treatment sealant to curtail reinfection. AAUS 20th Symposium Proceedings 2000. St. Pete Beach, Fl, p 10-11

Hunter CL, Evans CW (1995) Coral reefs in Kāne'ohe Bay, Hawai'i: two centuries of western influence and two decades of data. Bull Mar Sci 57:501-515

Jokiel PL (1978) Effects of water motion on reef corals. J Exp Mar Biol Ecol 35:87-97

*Miller MW, Williams DE (2007) Coral disease outbreak at Navassa, a remote Caribbean island. Coral Reefs 26: 97-101

* Nandakumar R, Babu S, Viswanathan R, Raguchander T, Samiyappan R (2001) Induction of systemic resistance in rice against sheath blight disease by Pseudomonas fluorescens. Soil Biol Biochem 33:603-612

*Page CA, Willis BL (2008) Epidemiology of skeletal eroding band on the Great Barrier Reef and the role of injury in the initiation of this widespread coral disease. Coral Reefs 27:257-272

Raymundo LJ, Couch CS, Harvell CD (eds) (2008) Coral disease handbook - guidelines for assessment, monitoring \& management. https://www.nwhc.usgs.gov/hfs/Globals/ Products/Coral\%20Disease\%20Handbook.pdf

* Sheppard C, Dixon DJ, Gourlay M, Sheppard A, Payet R (2005) Coral mortality increases wave energy reaching shores protected by reef flats: examples from the Seychelles. Estuar Coast Shelf Sci 64:223-234

Ushijima B, Smith A, Aeby GS, Callahan SM (2012) Vibrio owensii induces the tissue loss disease Montipora white syndrome in the Hawaiian reef coral Montipora capitata. PLOS ONE 7:e46717

*Van de Water JAJM, Ainsworth TD, Leggat W, Bourne DG, Willis BL, van Oppen MJH (2015) The coral immune response facilitates protection against microbes during tissue regeneration. Mol Ecol 24:3390-3404

*Warrell MJ, Riddell A, Yu LM, Phipps J and others (2008) A simplified 4-site economical intradermal post-exposure rabies vaccine regimen: a randomised controlled comparison with standard methods. PLOS Negl Trop Dis 2: e224

Williams GJ (2013) Contrasting recovery following removal of growth anomalies in the corals Acropora and Montipora. Dis Aquat Org 106:181-185

Work TM, Aeby GS (2010) Wound repair in Montipora capitata. J Invertebr Pathol 105:116-119

*Work TM, Russell R, Aeby GS (2012) Tissue loss (white syndrome) in the coral Montipora capitata is a dynamic disease with multiple host responses and potential causes. Proc R Soc Lond B Biol Sci 279:4334-4341

Submitted: September 30, 2016; Accepted: November 28, 2016 Proofs received from author(s): January 30, 2017 